\title{
O ENSINO DE PROBABILIDADE E ESTATÍSTICA PARA ESTUDANTES COM DEFICIÊNCIA VISUAL: O USO DO MULTIPLANO PARA CALCULAR MODA, MÉDIA E MEDIANA
}

\section{TEACHING OF PROBABILITY AND STATISTICS FOR STUDENTS WITH VISUAL DEFICIENCY: THE USE OF MULTIPLAN TO CALCULATE FASHION, AVERAGE AND MEDIAN}

Wesley Matheus Moura Balbino ${ }^{1}$; Cleiton Pedrosa de Sales ${ }^{2}$; Isabel Bezerra Lima ${ }^{3}$; Welson Costa Pimenta ${ }^{4}$; Francismar Holanda ${ }^{5}$

\section{INTRODUÇÃO}

Tem-se criado políticas que facilitam a inclusão de estudantes com deficiência na educação brasileira, visando melhorar o seu desempenho em sala de aula, assim como, a qualidade do ensino ofertado para esse público. Ocorre, nacionalmente, um movimento em prol do desenvolvimento de metodologias e perfis pedagógicos que reconheçam esses estudantes e proporcionem o aumento das habilidades relacionadas aos conteúdos programáticos, em especial, na matemática.

Pensando nisso, com base nos estudos de especialistas voltados à educação especial, decidiu-se elaborar um material concreto didático voltado para o ensino de probabilidade e estatística, para pessoas com deficiência visual. De acordo com os dados obtidos pelo Sistema de Avaliação da Educação Básica (Saeb) de 2015, a matemática enfrenta grandes desafios para que os estudantes brasileiros produzam uma aprendizagem significativa, em vista dos baixos índices de desempenho, e tal estatística não se faz diferente em relação ao desenvolvimento dos alunos com deficiência nessa área do saber, assim como também, essa dificuldade de aprendizado prejudica o entendimento de conceitos básicos para outras disciplinas como, por exemplo, o ensino de biologia.

Quando se trata da formação inicial de professores no curso de Ciências biológicas, também temos a dificuldade dos estudantes em compreender conteúdos relacionados ao estudo da Bioestatística, disciplina qual compõe a grade curricular desse curso.

\footnotetext{
${ }^{1}$ Licenciando em Matemática, Instituto Federal de Educação, Ciência e Tecnologia do Piauí - Campus Teresina Central, wesleymathifpi@gmail.com

${ }^{2}$ Licenciando em Matemática, Instituto Federal de Educação, Ciência e Tecnologia do Piauí - Campus Teresina Central, csales.ifpi.edu@gmail.com

${ }_{3}^{3}$ Licenciando em Matemática, Instituto Federal de Educação, Ciência e Tecnologia do Piauí - Campus Teresina Central, isabelblima1@gmail.com

${ }^{4}$ Licenciando em Ciências Biológicas, Instituto Federal de Educação, Ciência e Tecnologia do Piauí - Campus Teresina Central, linconpimenta@gmail.com

${ }^{5}$ Professor Mestre, Instituto Federal de Educação, Ciência e Tecnologia do Piauí - Campus Teresina Central, frholanda@ifpi.edu.br
} 


\section{FUNDAMENTAÇÃO TEÓRICA}

Durante a formação inicial, depara-se com situações que se faz necessária a mudança metodológica no ensino, para haver a inclusão de alunos com deficiência visual. No âmbito escolar, dessa forma, é preciso uma adequação quanto às metodologias de ensino de matemática. Para que haja o exercício pleno do direito de acesso à educação de qualidade pelo estudante com deficiência. Campos e Silva Sá (2007, p. 13), afirma que os conteúdos escolares privilegiam a visualização em todas as áreas de conhecimento, de um universo permeado de símbolos gráficos, imagens, letras e números"'.

Sabe-se que a exclusão vivenciada na sociedade é alvo de discussão para amenizar esse problema social. Tal problema, possui como possibilidade para diminuir a inclusão social, a fim de que os direitos das pessoas com ou sem deficiência pudessem ser tratados com equidade e tal afirmação está em consonância com Sassaki (1997). Com a inclusão social objetiva-se construir uma sociedade que trate de forma a respeitar os direitos de todos os cidadãos, como por exemplo: segurança, saúde, educação; assim como afirma Mendonça (2007), tal avanço social contribuiria para que a educação matemática alcance efetivamente as pessoas com deficiência.

Sendo a matemática uma matéria predominantemente baseada em interpretação e visualização mental das soluções para os problemas indagados, para que o deficiente visual possa ter acesso a esse conhecimento, é de suma importância que se tenha atrelado à metodologia de ensino a didática que envolve o uso de recursos didáticos que promovam a visualização concreta para então o problema ser compreendido mentalmente pelos estudantes.

\section{METODOLOGIA}

O presente trabalho foi realizado no Instituto Federal de Educação, Ciência e Tecnologia do Piauí - Campus Teresina Central, com alunos com deficiência visual do curso de Licenciatura em Ciências Biológicas. Sua natureza tem caráter qualitativo experimental, buscando analisar a eficácia do recurso concreto-didático denominado Multiplano, proposto para o ensino de média, moda e mediana também podem encontrar esse conteúdo no ensino de biologia quanto, principalmente, na genética.

O experimento foi realizado em três etapas: primeiramente foi exposto o conteúdo em questão, de forma oral analisando os pontos em que os alunos apresentam maior dificuldade para o entendimento. Na segunda etapa, após identificar a dificuldade dos alunos em interpretar os conceitos iniciais de moda, mediana e média foi elaborado um material concreto com a 
finalidade de amenizar essas dificuldades, a partir disso aplicou-se o material com os discentes a fim de recolher as contribuições do mesmo.

A início, para haver uma melhor explanação dos conteúdos mencionados por meio do material, foi proposto o seguinte exemplo: "Numa sala de aula contendo seis alunos, após a prova final, as notas dos alunos foram respectivamente, as seguintes: 9, 2, 6, 4, 2 e 7. Qual é a média, moda e Mediana das notas obtidas?". Na imagem a seguir, temos os números obtidos por meio das informações dadas no problema organizado no gráfico. Essa técnica consiste em dispor as informações de maneira que se consiga obter uma visualização mais organizada delas para responder com maior precisão o que está sendo pedido.

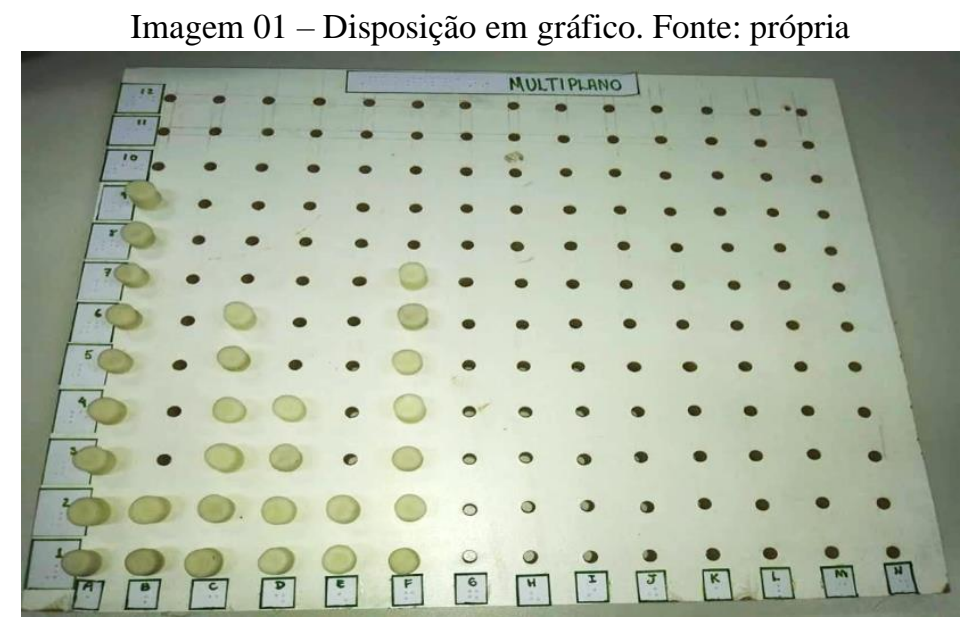

O referido recurso didático foi construído com a utilização de uma tábua de madeira, com as dimensões $40 \mathrm{~cm}$ x $40 \mathrm{~cm}$, composta por 14 furos na horizontal e 12 furos na vertical, e os seus "pinos" foram feitos com o uso de biscuit. Agora por meio da definição de Rol, que consiste em ser o arranjo dos dados brutos em ordem crescente ou decrescente. Executou-se a segunda organização das informações dispostas no exemplo promovendo assim o desenvolvimento da habilidade. Já com a organização em Rol, basta apenas pegar os dois termos centrais e dividir por dois, encontrando assim a mediana dessa sequência explicando a ligação entre esses conteúdos.

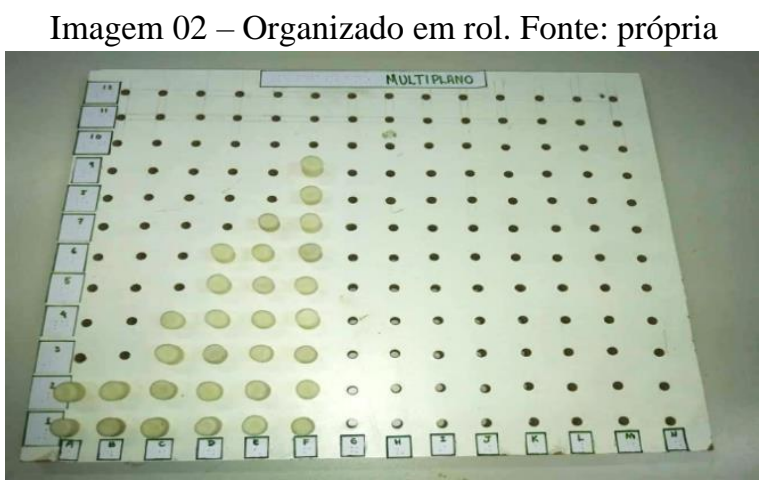


A seguir foi esclarecido os conceitos de moda, os quais se remetem ao número que mais se repete. No exemplo utilizado, questiona-se existe na situação problema apresentada uma nota que se repetia com maior frequência, ou seja, a moda. Para que os estudantes com deficiência respondessem a isso, eles tiveram que identificar no gráfico essa nota, como mostrada na imagem a seguir.

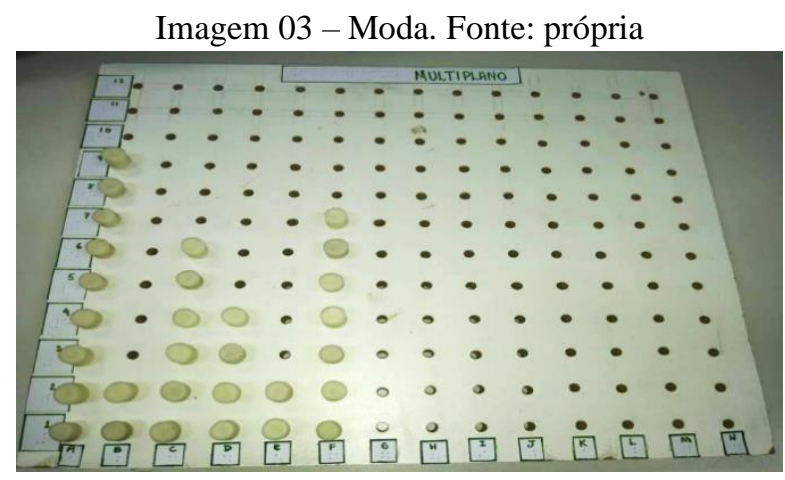

Sabendo que o conceito de média em probabilidade e estatística é uma medida de posição que indica o valor uniforme dos dados. Na figura 4 podemos observar das 6 fileiras, todas possuem a mesma quantidade de pinos (5), logo a média é igual a 5, e assim, o estudante compreendeu o conceito de média a partir da visualização de que toda vez que as fileiras tiveram a mesma quantidade de pinos a média será essa quantidade.

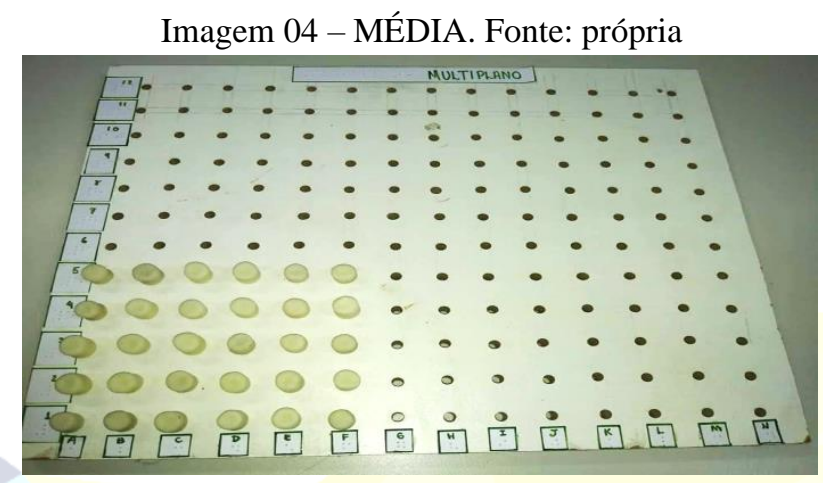

\section{RESULTADOS E DISCUSSÃO}

Como dito anteriormente, o presente trabalho teve caráter qualitativo, buscando analisar o impacto de um recurso didático concreto no ensino de probabilidade e estatística. Primeiramente, foi aplicado um questionário composto por cinco questões para o aluno identificar a média, moda e mediana sem o uso do recurso didático, e o resultado alcançado foi exposto no gráfico abaixo.

Após a explanação do funcionamento do recurso didático, novamente foi aplicado um questionário com cinco questões do mesmo nível das anteriores e o resultado foi o exposto a seguir. Pudemos observar a importância de metodologias alternativas para o ensino de pessoas 
com deficiência visual, principalmente quando se trata de matemática, uma matéria considerada por muitos como a ciência dos gênios.

GRÁFICO 01 - Representação gráfica das respostas certas e erradas sem o uso do uso do recurso didático. Fonte Própria

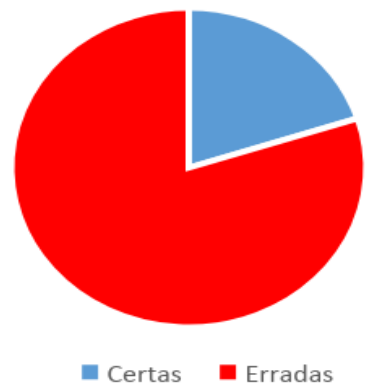

GRÁFICO 02 - Representação gráfica das respostas certas e erradas com o uso do uso do recurso didático. Fonte Própria

\section{Representação gráfica do percentual de respostas certas e erradas com o uso do recurso didático.}

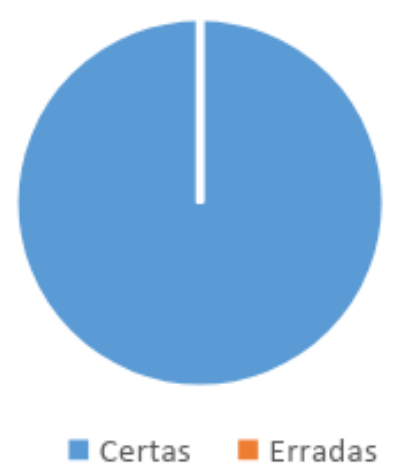

Durante o experimento, foi notável o envolvimento e emoção dos alunos que participaram, os mesmos demonstraram muita satisfação em conseguir responder o questionário com o uso do recurso didático.

\section{CONCLUSÕES}

Este estudo proporcionou uma experiência positiva que possibilitará uma melhoria na formação do profissional de educação, no que tange a educação especial, bem como promover com esse aprendizado a conscientização e a sensibilização, perante as dificuldades de aprendizado dos estudantes com deficiência, o fortalecendo da relação professor-aluno e alunoaluno em vista da preocupação quanto ao desenvolvendo de competências de ambos.

O Art. 1 da Lei $\mathrm{N}^{\circ}$ 13.146, assegura e promove, em condições de igualdade, o exercício dos direitos e das liberdades por pessoa com deficiência, visando à sua inclusão social e cidadania. Porém o que se observa na graduação é algo bem diferente do que é proposto pela 
lei. Entretanto é nosso dever, como cidadãos e futuros profissionais de educação, entrarmos com uma proposta metodológica para que haja essa inclusão de fato.

Ao final dessa experiência, podemos concluir, de fato, que essa iniciativa pode ajudar muitos alunos com deficiência visual, pois, pode-se observar foi que o uso desse material concreto possibilitou a esses alunos construir gráficos com suas próprias mãos, passando a ser, não apenas, um mero receptor de conteúdo mais um agente no processo ensino-aprendizagem, estimulando sua autonomia e desenvolvendo as competências necessárias para o entendimento mais aprofundado desse conteúdo.

\section{REFERÊNCIAS}

BRASIL. Portal Inep - SAEB. Brasília. Disponível em: http://portal.inep.gov.br/artigo//asset_publisher/B4AQV9zFY7Bv/content/inep-apresenta-resultados-do-saeb-prova-brasil2015/2120.

Francelin, Madalena Aparecida S.; Motti, Telma F. G.; \& Morita, Ione. (2010). As implicações sociais da deficiência auditiva adquirida em adultos. Saúde e Sociedade, 19(1), 180-192

KOEPSEL, A. Materiais Didáticos no ensino de Matemática para estudantes com deficiência visual. In: XX EBRAPEM: Encontro Brasileiro de Estudantes de Pós-Graduação em Educação Matemática, 2016, Curitiba.

Lei $\mathrm{n}^{\circ}$ 13.146, de 6 de julho de 2015. Institui a Lei Brasileira de Inclusão da Pessoa com Deficiência (Estatuto da Pessoa com Deficiência). Disponível em:

http://www.planalto.gov.br/ccivil_03/_Ato2015-2018/2015/Lei/L13146.htm. Acessado em 06de outubrode 2018.

LOPES, Maura Corcini; FABRIS, Eli Henn; Inclusão e Educação. São Paulo: Autêntica, 2013.

MENDONÇA, E. Inclusão social: seu papel na transformação da sociedade. Revista Mercado. Disponível em: . Acesso em: 15 fev. 2007

SASSAKI, R. K. Abordagens sócio-antropológicas em educação especial. In: SKLIAR, C. (Org.). Educação e exclusão. Porto Alegre: Editora Mediação, 1997. 